\title{
Bozulmamış Sediment Örnekleyici Kullanılarak Kızılırmak (Nevşehir-Türkiye) Nehri Sedimentlerinde Arsenik Ağır Metalinin Değerlendirilmesi
}

\author{
Ömer Bilhan ${ }^{*}$, Fatih İlalan ${ }^{2}$ \\ ${ }^{1}$ Nevşehir Hacı Bektaş Veli Üniversitesi, Nevşehir, Türkiye, (ORCID: 0000-0002-8661-6097; 0000-0001-6331-4638), omerbilhan@nevsehir.edu.tr, \\ fatihilalan@gmail.com
}

(2nd International Conference on Access to Recent Advances in Engineering and Digitalization (ARACONF)-10-12 March 2021)

(DOI: 10.31590/ejosat.900690)

ATIF/REFERENCE: Bilhan, Ö. \& İlalan, F. (2021). Bozulmamış Sediment Örnekleyici Kullanılarak Kızılırmak (Nevşehir-Türkiye) Nehri Sedimentlerinde Arsenik Ağır Metalinin Değerlendirilmesi. Avrupa Bilim ve Teknoloji Dergisi, (24), 302-308.

$\ddot{\mathbf{O} z}$

Son yıllarda akarsu ve göllerde çevre kirliliği araştırmaları hızlı bir şekilde artmıştır. Kızılırmak Nehri, hızlı kentleşme, sanayileşme ve antropojenik etkiler nedeniyle yüksek oranlarda ağır metal yükü taşımaktadır. Bu çalışmanın amacı, Nevşehir ili sınırlarından geçen Kızılırmak Nehrinin Gülşehir, Avanos ve Sarıhıdır hattında nehri tehdit eden kirleticilerden Arsenik (As) ağır metalinin, multisampler (bozulmamış sediment örnekleyici) cihazı kullanılarak alınan sediment örneklerindeki mevcudiyetini araştırmak ve analiz etmektir. Bu çalışma kapsamında, saha çalışmaları Orta Kızılırmak Havzası Nevşehir İli, Gülşehir ilçesi ve Sarıhıdır Köyü arasındaki bölgede gerçekleştirilmiştir. Bu bölgede, nehrin doğal akışı ve arazi yapısı da göz önüne alınarak, sediment örneklerinin toplanması için 7 örnekleme noktası tespit edilmiştir. Arsenik elementine ait analiz sonuçları değerlendirildiğinde, en yüksek değer $33 \mathrm{mg} / \mathrm{kg}$, olarak 4 . ve 7. lokasyonlardan alınan numuneler üzerinde belirlenmiş, minumum değer ise $11 \mathrm{mg} / \mathrm{kg}$ olarak 1 . Lokasyon üzerinden alınan numunede tespit edilmiştir. PEL, TEL, ERL ve Ref. sınır değerleri esas alındığında, tüm lokasyonlarda Arsenik için TEL sınır değerinin aşıldığı görülmektedir. Ayrıca, 2. Lokasyonun en yüksek ortalama As değerine sahip olduğu 6. Lokasyonun ise en düşük ortalama As değerine sahip olduğu belirlenmiştir.

Anahtar Kelimeler: Kızılırmak, Sediment, Ağır Metal, Arsenik, Kirlilik, Nevşehir.

\section{Evaluation in Term of Arsenic Contamination Kızlırmak River (Nevşehir, Turkey) Sediments by using Intact Sediment Multisampler}

\begin{abstract}
Environmental pollution research in rivers and lakes has increased rapidly in recent years. K1z1lırmak River carries high rates of heavy metal load due to rapid urbanization, industrialization and anthropogenic effects. The aim of this study is to investigate and analyze the presence of Arsenic (As) heavy metal, one of the pollutants threatening the river, in sediment samples taken using a multisampler in Gülşehir, Avanos and Sarıhıdır line of Kızılırmak River passing through the borders of Nevşehir province. Within the scope of this study, field studies were carried out in the region between the Orta Kızılırmak Basin, Nevşehir Province, Gülşehir district and Sarıhıdır Village. In this region, 7 sampling points were determined for the collection of sediment samples, taking into account the natural flow of the river and the terrain. When the analysis results of the arsenic element were evaluated, the highest value was determined as $33 \mathrm{mg}$ $/ \mathrm{kg}$ on the samples taken from the 4th and 7th locations, and the minimum value was determined as $11 \mathrm{mg} / \mathrm{kg}$ in the sample taken from the 1st location. PEL, TEL, ERL and Ref. based on the limit values, it is seen that the TEL limit value for Arsenic is exceeded in all locations. In addition, location 2 has the highest average As value and location 6 has the lowest average As value.
\end{abstract}

Keywords: Kizilirmak, Sediment, Heavy Metal, Arsenic, Pollution, Nevsehir.

\footnotetext{
*Sorumlu Yazar: omerbilhan@,nevsehir.edu.tr
} 


\section{Giriş}

Dünyamızda hızlı nüfus artışı ve insanların yaşam standartlarının yükselmesine bağlı olarak özellikle akarsular üzerine inşa edilen regülasyon yapılarının sayılarının artması, endüstri ve sanayi atıklarındaki kirliliğin göl ve nehir gibi alıcı ortamlara ulaşması ile içilebilir ve kullanılabilir su miktarında azalmalar ve su kalitesinde bozulmalar görülmektedir [1].

"Ağır metal" ifadesi günümüzde birçok farklı bilim alanında sıklıkla kullanılan bir terimdir. Günümüzde, literatürde kontaminasyon ve potansiyel toksisite veya eko-toksisite ile ilişkilendirilen metaller ya da yarı-metaller (metalloidler) olarak ifade edilirler. Genellikle ise ağır metal, tanımı yoğunluk, atomik ağırlık, kimyasal özellikler ya da toksisiteye bağlı olarak farklı tanımlamalarla ifade edilmektedir. Genel bir iafadeyle, ağır metal tanımı yoğunluğu $5 \mathrm{~g} / \mathrm{cm}^{3}$ 'den daha büyük olan metaller olarak ifade edilmektedir. Altmışın üzerinde element, ağır metallere örnek olarak gösterilebilsede en sık rastlanan ve en çok bilinen ağır metallere Kurşun (Pb), Arsenik (As), Civa (Hg), Mangan $(\mathrm{Mn})$, Demir (Fe), Kobalt (Co), Nikel (Ni), Bakır (Cu), Çinko (Zn), Kadmiyum (Cd), Krom (Sn), Gümüş (Ag) ve Selenyum (Se) örnek olarak sıralanabilir [2]. Akarsu ve göllerde kirletici etki yapan birçok faktör bulunmaktadır. Bu faktörler arasında; sanayi atıkları, organik maddeler, gübre atıkları, deterjanlar, pestisitler, petrol ve türevleri, bakteri ve virüsler gibi hastalık yapıcı canlılar, tuzluluk ve canlılarda toksik etki yapan maddeler siralanabilir. $\mathrm{Bu}$ kirletici kaynakların en önemlilerinden birini de toksik etki yapan ağır metaller oluşturur. Endüstriyel ve tarımsal faaliyetlerdeki yoğunlaşma ağır metal kirliliğinin artmasındaki en önemli etkenlerdendir. $\mathrm{Bu}$ durum akarsu ve göllerde bulunan canlı organizmaların hayatını tehdit edebilmekle birlikte insan yaşamını da tehdit etmektedir. Ağır metallerin düşük konsantrasyonlarda bile kanserojen, toksik ve mutajen etkilerinin bulunduğu düşünüldüğünde son derece önemli oldukları ve dikkate alınmaları gerektiği söylenebilir. Ayrıca uygun olmayan deşarjlar ve atmosferik taşınım yollarıyla sucul ortamlara karışan ağır metaller biyolojik olarak parçalanamadıkları için canlı organizmalarda birikme eğilimindedirler [3].

Antropojenik kaynaklardan gelen ağır metaller, atık su, endüstriyel çamur, nehirler, havadan girdiler, yağış ve toz çökeltmesi gibi farklı kaynaklardan çevre koşullarının tüm bileşenleri arasında bulunur [4]. Sedimentlerin, çeşitli analitik tekniklerle güvenilir bir şekilde ölçülebilen seviyelerde kirleticiler biriktirdikleri için, çevre kirliliğinin mükemmel göstergeleri olduğu kanıtlanmıştır [5]. Bu durum, sedimentleri hem doğal hem de antropojenik kaynaklardan gelen en ağır metaller için etkili bir değerlendirme aracı haline getirir. Arsenik yerkabuğunun yapısında en çok yeralan elementlerden bir tanesidir. Metaloid veya bir başka ifadeyle metal olmayan olarak sınıflandırılmaktadır. Eczacılık sektörü ve Tarım sektörü vb. endüstri dallarında kullanılmasının yanında, canlılar üzerinde toksik etkiye sahiptir. Arsenik kanserojenik olarak da bilinen zehirli bir element sınıfındadır. [6]. Amerika Çevre Koruma Ajansı almış olduğu yeni kararlarla, içme sularında arsenik için kabul edilen maksimum kirletici seviyesini $0.05 \mathrm{mg} / \mathrm{L}$ 'den 0.01 mg/L'ye düşürmüştür. Dünya Sağlık Örgütü (WHO), bünyesinde bu değer 1993 yılında $0.01 \mathrm{mg} / \mathrm{L}$ ye düşürülmüştür [7]. Türkiye'de “İnsani Tüketim Amaçlı Sular” Yönetmeliğinde Şubat 2008 'den itibaren arsenik için izin verilen sınır değeri 10 ppb olarak kabul edilmiştir [8].
İnsan aktiviteleri sonucunda ortaya Arsenik kirliliğinin başlıca sebepleri arasında, cam, metal ve seramik endüstrisi, lastik, boya sanayi, petrol sanayi, organik ve inorganik kimya sektörlerinde arsenik içeren atıklar ve bu atıkların yeterince kontrol edilmediği endüstri kaynakları yer almaktadır [5-8]. Bu antropojenik etkiler sonucu ortaya çıkan arsenik içerikli atıklar, su ve toprak kirliliğine neden olmasının yanında, yüzeysel sulara ve özellikle tarımsal aktiviteleri nedeniyle içme sularımıza karışabilmektedir. Arsenikle kirlenmiş yeraltı sularının sulama amaçlı kullanımı, tarımda ve gıda sektöründe ciddi riskler oluşturarak toplum sağlığını tehdit etmektedir. Bunun bir sonucu olarak, özellikle arsenik oranı yüksek atıksuların alıcı ortamlara aktarılmadan önce arıtılırak arındırılması gerekmektedir. Arsenik uzaklaştırılmasında kullanılan teknikler, kimyasal çöktürme, adsorpsiyon, filtrasyon, membran sistemler, pıhtılaştırmayumaklaştırma, iyon değişimi vb. gibi arıtma teknolojileridir. Bununla birlikte, doğal su kaynakları, insan sağlı̆̆ını tehdit edecek düzeyde yüksek konsantrasyonlarda arsenik içeriyorsa, bu su kaynaklarının kullanılmadan önce arıtma işlemlerinin uygulanması gerekmektedir.

Topal, M., ve Topal, E.I.A., [9] içme ve sulama suyu olarak kullanılan Keban Baraj Gölü'nde arsenik konsantrasyonları belirlenmiş ve ITASHY'de belirtilen sınır değerle karşılaştırmışlardır. Tunca, Ü.E, [10] çalışmasında, Beyşehir Gölü üzerindeki istasyonlarda su ve sedimentteki ağır metal kirliliğinin belirlenmesi ve sedimentteki antropojenik etkinin oluşturduğu kirliliği değerlendirmiştir. Akyıldız, M. ve Karataş, M. [11] Adana ili çevresinde, Topraklarda Ağır Metal Kirliliğinin Araştırılması amacıyla, bölgeden 52 adet örnek alarak, alınan örnekler üzerinde Atomik Absorbsiyon Spektrometre cihazı ile $\mathrm{Fe}, \mathrm{As}, \mathrm{Al}, \mathrm{Mn}, \mathrm{Zn}, \mathrm{Cu}, \mathrm{Hg}, \mathrm{Ni}, \mathrm{Cr}, \mathrm{Pb}, \mathrm{Co}, \mathrm{Cd}$, elementlerine ait ağır metal analizleri gerçekleştirmişlerdir.

Wang ve diğg. [12] Kızılırmak Nehir tabanından elde ettiği bozulmamış sediment çekirdeği için $\mathrm{Cu}, \mathrm{Pb}, \mathrm{Zn}, \mathrm{Ag}, \mathrm{Ni}, \mathrm{Co}, \mathrm{Mn}$, $\mathrm{As}, \mathrm{Cd}, \mathrm{Sb}, \mathrm{V}, \mathrm{Cr}, \mathrm{Hg}$ ve $\mathrm{Se}$ ağır metallerinin zamansal değişimlerini radyonuklit analiz gerçekleştirerek incelemişlerdir.

$\mathrm{Bu}$ çalışmada, Nevşehir ili sınırlarından geçen Kızılırmak Nehrinin Gülşehir, Avanos ve Sarıhıdır hattı üzerinde, nehri tehdit eden kirleticilerden Arsenik (As) ağır metalinin, multisampler (bozulmamış sediment örnekleyici) kullanılarak alınan sediment örneklerindeki mevcudiyetini araştırmak ve ön değerlendirme yapmak amaçlanmıştır.

\section{Materyal ve Metot}

\section{1.Çalışma Alanı}

Kızılırmak Nehri, İç Anadolu bölgesinin doğusunda yer alan Sivas iline bağlı İmranlı ilçesi civarında, Kızıldağ'ın güney yamaçlarından yaklaşık $39.8^{\circ}$ Kuzey, $38.8^{\circ}$ Doğu noktasından başlayarak, öncelikle Batı ve Güneybatı 'ya $38.7^{\circ}$ Kuzey, $34.8^{\circ}$ Doğu ya kadar akar, daha sonra yay şeklinde biçimlenir. Batıya doğru akışını sürdüren nehir, daha sonra Kuzeydoğudaki Tuz Gölü'nü geçerek Kuzeybatı 'ya akar. Daha sonra Kuzey ve Kuzeydoğu 'ya yönelir. Burada Delice Irmağı ile Batı noktasında birleşir. Sonuçta Karadeniz'e $41.72^{\circ}$ Kuzey $35.95^{\circ}$ Doğu noktasında boşalır. Sırasıyla Sivas, Kayseri, Nevşehir, Kırşehir, Kırıkkale, Ankara, Aksaray, Çankırı, Çorum ve Samsun illeri sınırları içerisinden geçerken, bölgede çok sayıda akarsu, dere ve çayın sularını bünyesinde toplayarak Bafra Burnu'ndan Karadeniz'e deşarj olur. Düzensiz bir rejime sahip olan Kızılırmak Nehri, kar ve yağmur sularıyla beslenir. Temmuz ve Şubat ayları 
arasında düşük debilerle akan nehir, Mart ayında hızla kabarmaya başlar ve Nisan ayında en yüksek debiye ulaşır. Nehrin ortalama debisi yaklaşık $184 \mathrm{~m}^{3} / \mathrm{sn}$ 'dir. Kızılırmak Nehri üzerine inşa edilen en önemli su yapılarını değerlerndirirsek, Kayseri yakınlarında Sarığlan Barajı, Yemliha yöresinde Yamula Barajı, Ankara yakınlarında Hirfanlı, Kesikköprü ve Kapulukaya barajları, Çorum yakınlarında inşa edilen Obruk Barajı, Boyabat yakınlarında inşa edilen Boyabat Barajı ile Kızılırmak Nehri'nin denize dejarj olduğu bölgeye yakın, Bafra Ovası üzerinde yer alan, Altınkaya ve Derbent barajları ön plana çıkar. Kızılırmak Nehri'ni Türkiye'deki diğer nehirlerden ayıran en önemli özelliklerden biri, havzanın değişik formasyonlar içermesidir. Kızılırma Nehri Drenaj alanının yaklaşık \% 60'lık bölümünü volkanik tüfler oluşturmakta ve bu formasyonlardaki yatak malzemesi ve havza malzemesinin özgül ağırlığı ise $1,6 \mathrm{t} / \mathrm{m}$ civarında olması, diğer sediment malzemesinin özgül ağırlığının $2,6 \mathrm{t} / \mathrm{m}$ ortalama değerine sahip olması, ask1 yükü sediment taşımınım oranını Türkiye'deki diğer nehirlere göre farklılaştırmaktadır.

Orta Kızılırmak Havzası içerisinde yer alan Nevşehir İli ve çevresi değerlendirildiğinde, tarım arazilerinin yanlış kullanımı, ormanlık alanların tahribatı, endüstriyel atıklar ve diğer antropojenik etkilerle birlikte sediment bütçesinin bozulduğu görülmektedir. Özellikle Gülşehir İlçesinin batısından, Avanos İlçesi Sarıhıdır Köyü'nün doğusunda yer alan Bayramhacılı Barajı'na kadar, Kızılırmak Nehri üzerinde inşa edilen ve inşa halinde olan regülasyon yapılarının bölgede nehrin doğal akışını engelleyerek sediment taşınımını olumsuz yönde etkilediği belirlenmiştir. Nehirdeki doğal sedimentasyonun bozulmasında diğer bir ifadeyle nehrin kirlenmesinde en önemli neden, insan etkisidir (antropojenik etkiler). Doğal bitki örtüsünün tahribat1, tarım arazilerinin bilinçsiz kullanımı gibi insan kaynaklı etkiler nehirlerdeki sediment birikimini olumsuz yönde etkiler.

$\mathrm{Bu}$ çalışma kapsamında, saha çalışmaları Orta Kızılırmak Havzasında yer alan Nevşehir İli sınırları içerisinde tamamlanmıştır (Tablo 1 ve Şekil 1). Orta Anadolu'da yer alan Nevşehir ili, yaklaşık 38-390 - kuzey enlemi ve $34-35^{0}$ doğu boylamı arasındadır. Konum olarak, Türkiye'nin neredeyse tam ortasında yer alır. Kentin Alanı 5467 km²'dir. Orta Anadolu'da yaygın bir toprak türü olan kahverengi topraklar Nevşehir de geniş bir yelpazeyi kaplar. Erciyes volkanik alanı yine bu bölgenin sınırlarına yakın konumlanmıştır.

Tablo1. Saha çalışmalarının yürütüldüğü örnekleme noktalarına ait koordinatlar

\begin{tabular}{c|c}
\hline Örnekleme Noktası & Koordinat \\
\hline $\mathbf{1}$ & $38^{0} 45.388961^{\prime} \mathrm{N}-34^{0} 37.077961^{\prime} \mathrm{E}$ \\
\hline $\mathbf{2}$ & $38^{0} 43.482521^{\prime} \mathrm{N}-34^{0} 49.182266^{\prime} \mathrm{E}$ \\
\hline $\mathbf{3}$ & $38^{0} 43.054462^{\prime} \mathrm{N}-34^{0} 50.917370^{\prime} \mathrm{E}$ \\
\hline $\mathbf{4}$ & $38^{0} 42.974312^{\prime} \mathrm{N}-34^{0} 51.588608^{\prime} \mathrm{E}$ \\
\hline $\mathbf{5}$ & $38^{0} 43.391777^{\prime} \mathrm{N}-34^{0} 52.354301^{\prime} \mathrm{E}$ \\
\hline $\mathbf{6}$ & $38^{0} 44.058067^{\prime} \mathrm{N}-34^{0} 55.854469^{\prime} \mathrm{E}$ \\
\hline $\mathbf{7}$ & $38^{0} 45.439403^{\prime} \mathrm{N}-34^{0} 41.194519^{\prime} \mathrm{E}$ \\
\hline
\end{tabular}

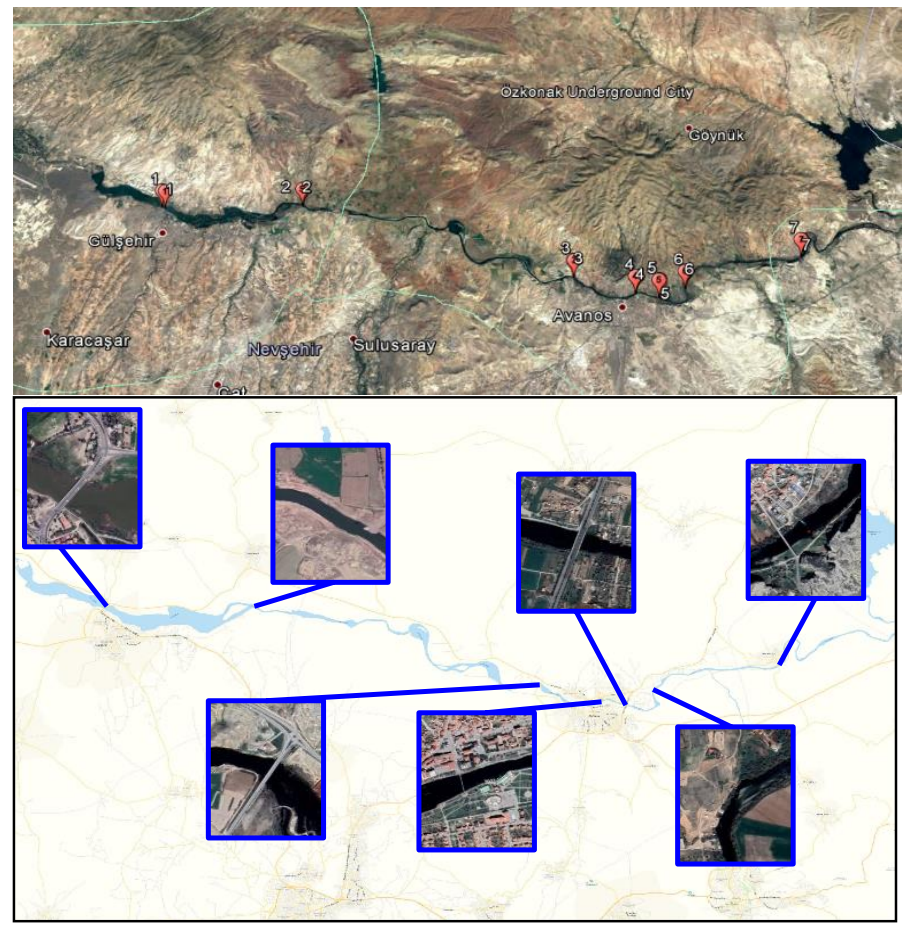

Şekil 1. Saha çalışmalarının gerçekleştirildiği örnekleme noktalart

Kızılırmak Havzasının net toplam su potansiyeli yaklaşık 6.544 milyar $\mathrm{m}^{3} / \mathrm{y} 1$ 'dır. Havzanın çoğu bölgesi tarım alanları ve ormanlarla kaplıdır veya yarı doğal alanlardır. Tarımsal alanlar, ormanlık alanlar, yarı doğal alanlar, sulak alanlar, su yüzeyi ve havzanın yapay alanları sirasiyla \% 54.68, \% 42.74, \% 0.34, \% 0.94 ve \% 1.3'tür [13]. Kuzey ve Orta Kızılırmak Havzası alanlarının, nüfus yoğunluğuna sahip olması ve evsel atıkların yanı sıra sanayilerin çoğundan çıkan atıklar nehre veya nehre boşaltıldığından dolayı, oldukça fazla kirletici yük aldığı belirlenmiştir [14]. Yüksek kapasiteli barajların varlığı ve işletilmesi, bölgenin nüfus yoğunluğu Türkiye nüfusunun üzerinde olduğundan, nehrin doğal yapısında bozulmalar görülmektedir.

\subsection{Saha çalışmalarında kullanılan cihazlar}

Nevşehir H. B V. Üniversitesi NEUBAP14F4 Numaralı bilimsel araştırma projesi kapsamında 2014 yılı Haziran ayında gerçekleştirilen saha çalışmaları, Kızılırmak Nehri üzerinde belirlenen, 7 örnekleme noktasında, Eijkelkamp Multisampler Bozulmamış Sediment Örnekleyici (Şekil 2 (a)) kullanılarak, nehir tabanından bozulmamış sediment karot örnekleri alınmıştır. Ayrıca, gelecek yıllarda daha genişletilmiş araştırmalarda kullanılmak üzere, debi ölçümleri ve nehrin taban topoğrafyasının çıkarılması amacıyla Şekil 2 (b)'de görülen RiverRay ADCP Stream Pro ADCP - Hemisphere A325 DGPS cihazı kullanılmıştır. Ayrıca bu cihaz üzerinde yer alan GPS yardımıyla koordinatların tespiti gerçekleştirilmiştir. $38^{\circ} 45.388961^{\prime} \mathrm{N}$ 34º37.077961'E Koordinatından alınan 1 numaralı örnekleme noktasına ait veriler Şekil 3'de örnek olarak sunulmuştur. 


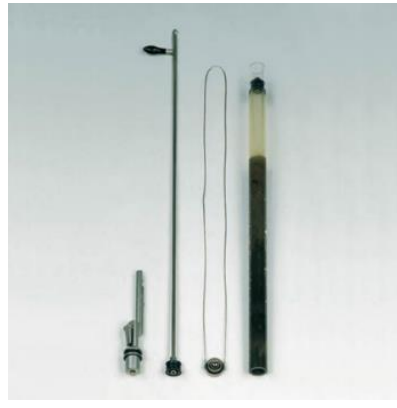

(a)

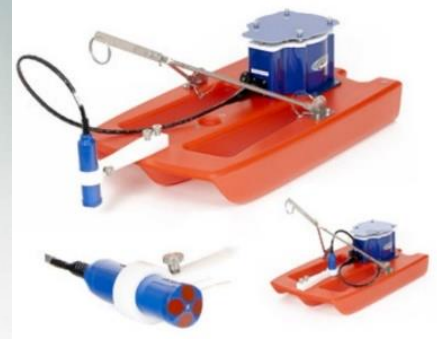

(b)

Şekil 2. (a) RiverRay ADCP (Acoustic Doppler Current Profiler) Hemisphere A325 DGPS Çok Yönlü Debi ve Taban Topoğrafyası Ölçüm Cihazl, (b) Eijkelkamp Multisampler Bozulmamış Sediment Örnekleyici

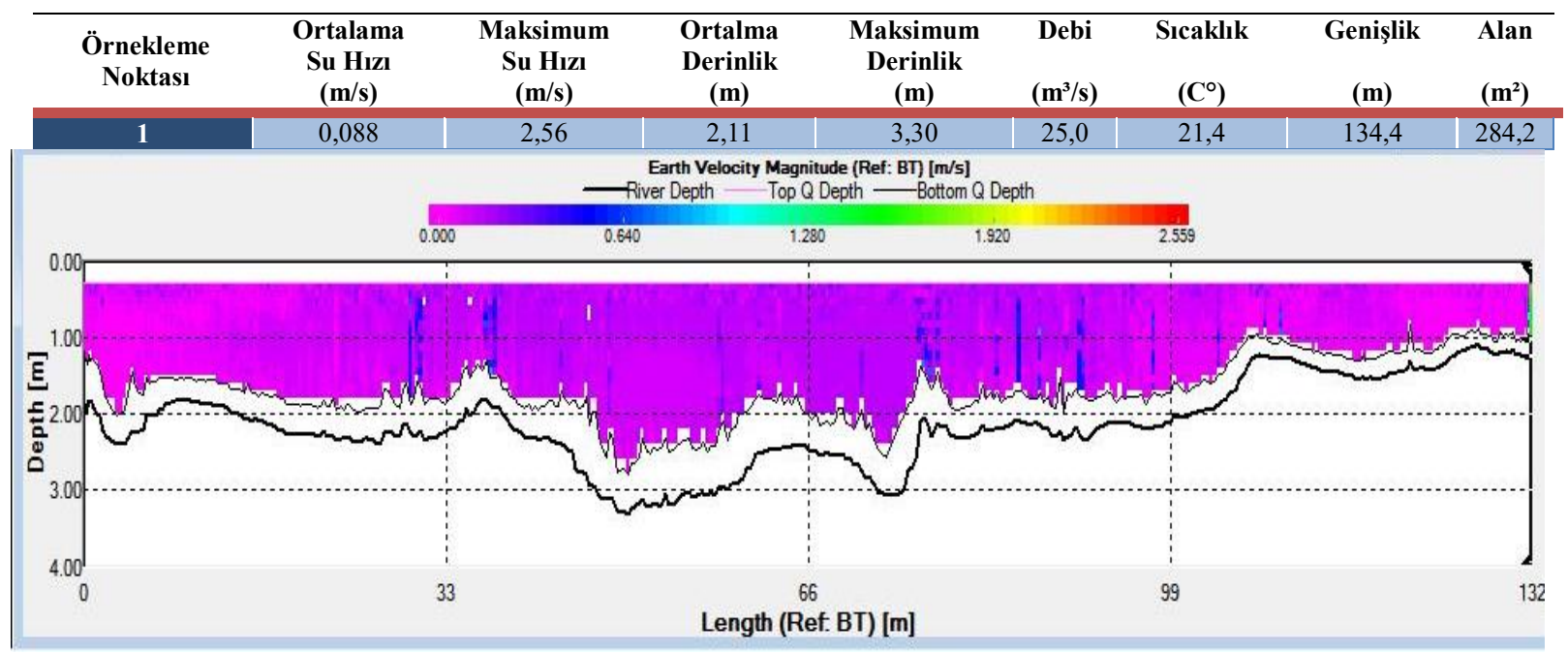

Şekil 3. RiverRay ADCP (Acoustic Doppler Current Profiler) A325 DGPS cihazı ile yapılan ölçümler sonucunda 1. Örnekleme noktasından alınan hidrolik ve hidrolojik veriler.

\subsection{Sediment Numunelerinin Nehir Tabanından Alınması}

$\mathrm{Bu}$ çalışma kapsamında, sediment numuneleri 2014 yılı Haziran ayı içerisinde Orta Kızılırmak Havzası Nevşehir ili Gülşehir İlçesi ile Sarıhıdır Köyü arasındaki hat boyunca belirlenen 7 ayrı örnekleme noktasından toplanmıştır. Bu koordinatlarda, Eijkelkamp Multisampler Bozulmamış Sediment Örnekleyici cihazı kullanılarak toplam 14 adet bozulmamış sediment karot numunesi nehir tabanından alınmıştır. Tablo 1 'de verilen koordinatlara göre 1 . Örnekleme noktasından çıkarılan sediment numunesinin boyu $74 \mathrm{~cm}$ olmak üzere, 2, 3, 4, 5, 6. ve 7. Örnekleme noktalarında sırasıyla $80,54,70,52,36$ ve 78 cm'lik uzunlukta sediment numuneleri alınmıştır. Her bir lokasyondan ağır metal analizleri için 1 tanesi yedek olmak üzere, 2 adet örselenmemiş sediment karot numunesi alınmıştır. Saha çalışmaları sırasında, sediment numuneleri çıkarıldıktan sonra, kuru buz yardımıyla dondurulmuş ardından laboratuvara taşınarak analizlerin gerçekleştirilmesine kadar $-80{ }^{\circ} \mathrm{C}$ 'de dondurucuda muhafaza edilmiştir (Şekil 4.)

Laboratuvarda muhafaza edilen donmuş haldeki sediment numuneleri ağır metal analizleri için seviyelendirme yapıldıktan sonra, laboratuvar ortamında kesilerek dilimlere ayrılmıştır. Dilimlere ayrılan sediment numuneleri etüvde $85^{\circ} \mathrm{C}$ kurutulmuştur. Elmas uçlu kesici ile seviyeler dikkate alınarak kesilen her bir numune isimlendirilip numaralandırılarak kayıt altına alınmıştır. 7 lokasyona ait her bir numune için tepe, orta ve dip (top, middle ve bottom) olarak belirlenen seviyelerden 2 şer numune alınıp etüvde kurutulduktan sonra ziplocked numune poşetlerine konularak ağır metal analizlerinin gerçekleştirilmesi amacıyla Kanada merkezli Acme Analitik Laboratuvar Hizmetleri Limited Şirketi'ne gönderilmiştir (Şekil 4).
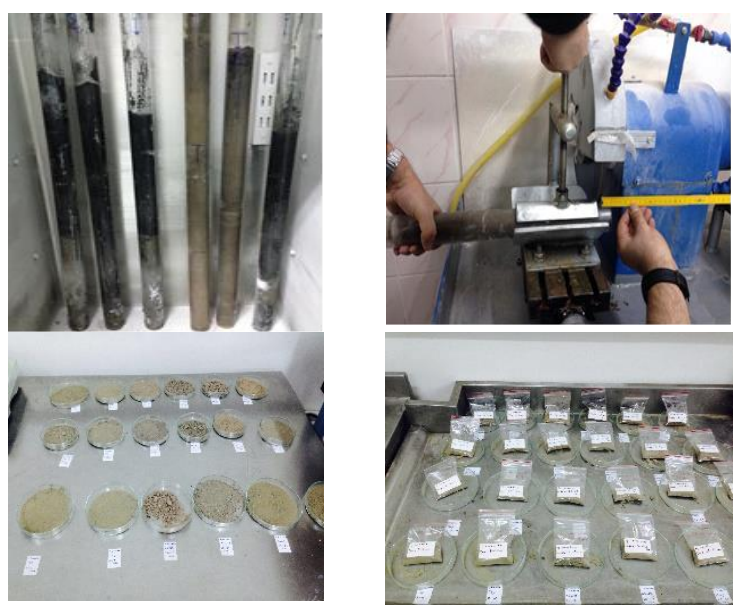

Şekil 4. Saha çalışmalarında sediment örneklerinin alınarak labaratuarda analize hazır hale getirilmesi. 


\section{Araştırma Sonuçları ve Tartışma}

Bu çalışma kapsamında, Kızılırmak Nehri Gülşehir-Sarıhıdır hattı üzerinde, 7 örnekleme noktasında, nehir tabanından bozulmamış sediment örnekleri alınmıştır. Alınan örneklerde seviyelere göre As (Arsenik) metal konsantrasyonları belirlenerek, sediment ortamlarının Arsenik kirliliği bakımından değerlendirmesi aşağıda verilmiştir (Şekil 5-11).

Ağır metal analizleri ACME Analytical Laboraties Ltd. (Kanada) analitik kimya laboratuarında ICP-ES cihazı kullanılarak gerçekleştirilmiştir. ICP-ES bir başka ifadeyle, indüksiyonla birleşmiş plazma atomik emisyon spektroskopisi (Inductively coupled plasma atomic emission spectroscopy/ICPES), aynı zamanda İndüksiyonla birleşmiş plazma optik emisyon spektroskopisi Inductively coupled plasma optical emission spectrometry/ICP-OES olarak da bilinen kimyasal elementlerin tespiti için kullanılan analitik bir tekniktir. Bu teknik ile iz elementlerde alt analiz limitleri değerlendirildiğinde As için MDL (The Method Detection Limit) gözlenebilme sınır değeri, 5 ppm olarak belirtilmiştir.

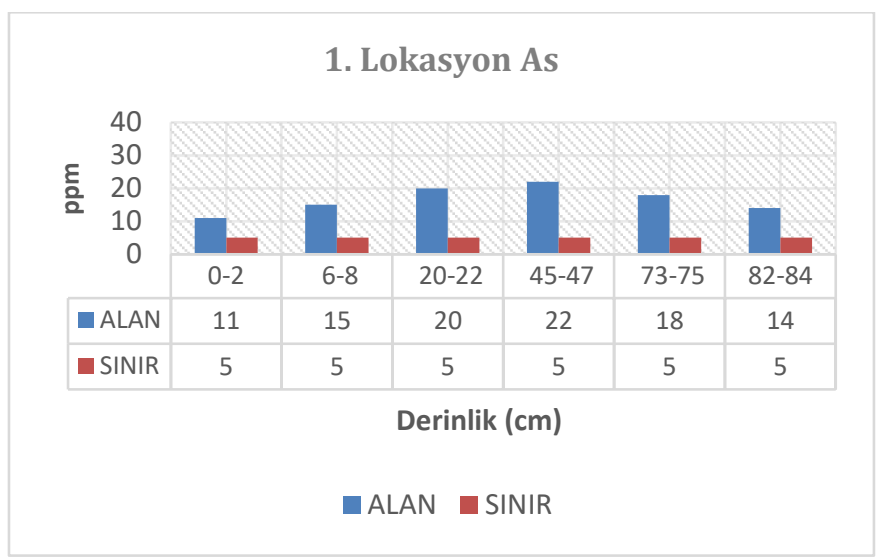

Şekil 5. 1. Lokasyondan alınan numune Arsenik değerleri

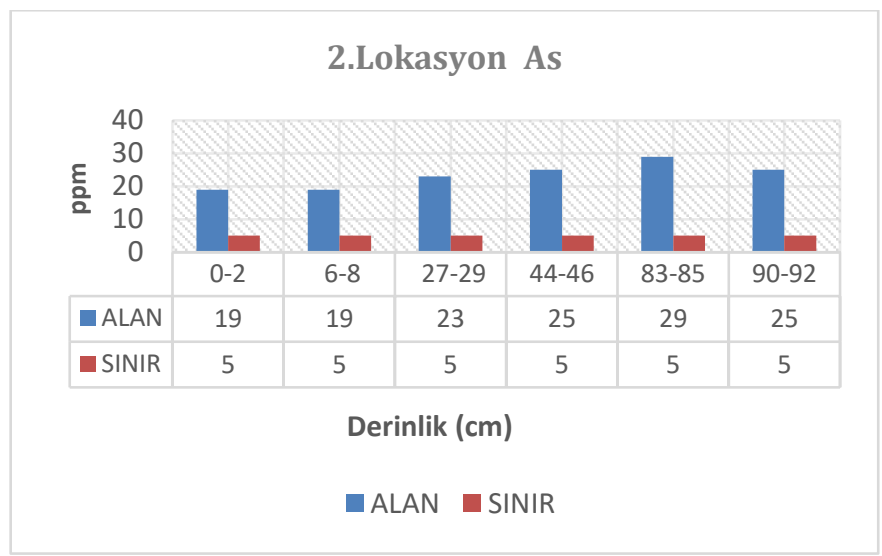

Şekil 6. 2. Lokasyondan alınan numune Arsenik değerleri

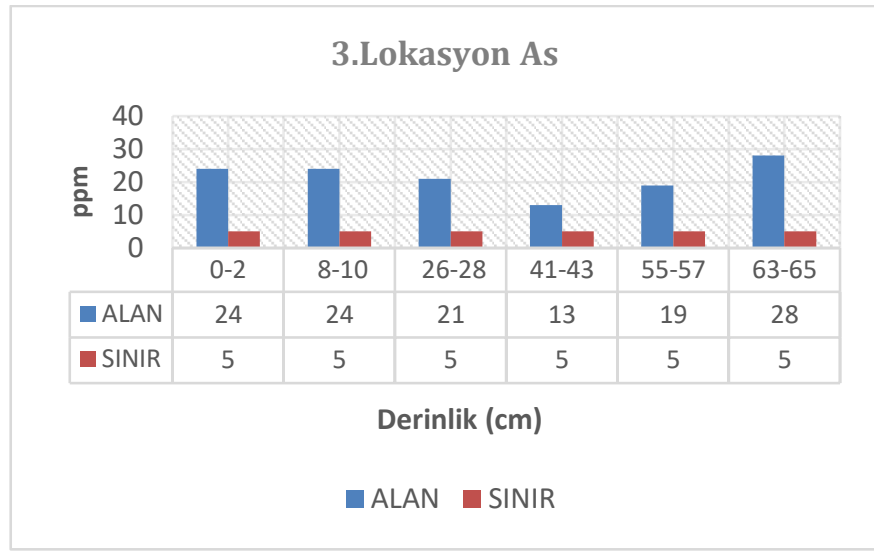

Şekil 7. 3. Lokasyondan alınan numune Arsenik değerleri

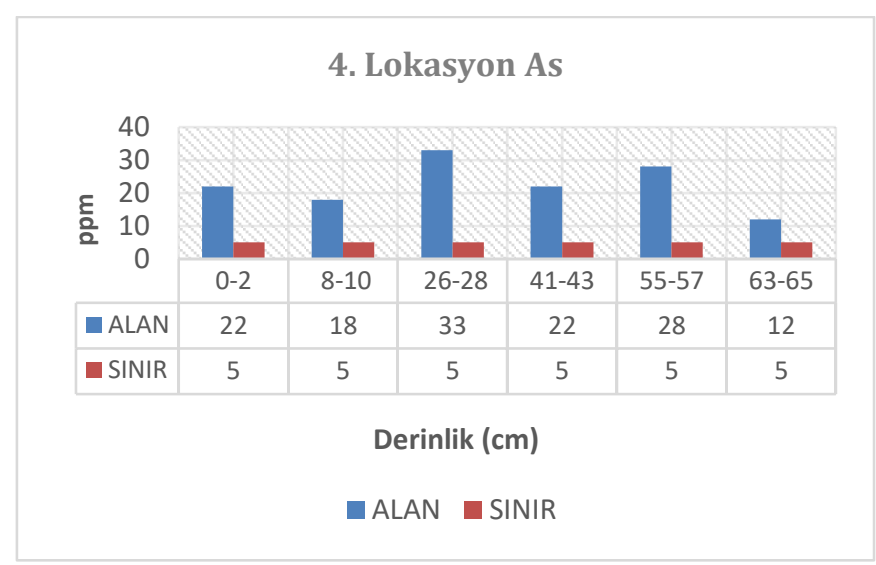

Şekil 8. 4. Lokasyondan alınan numune Arsenik değerleri

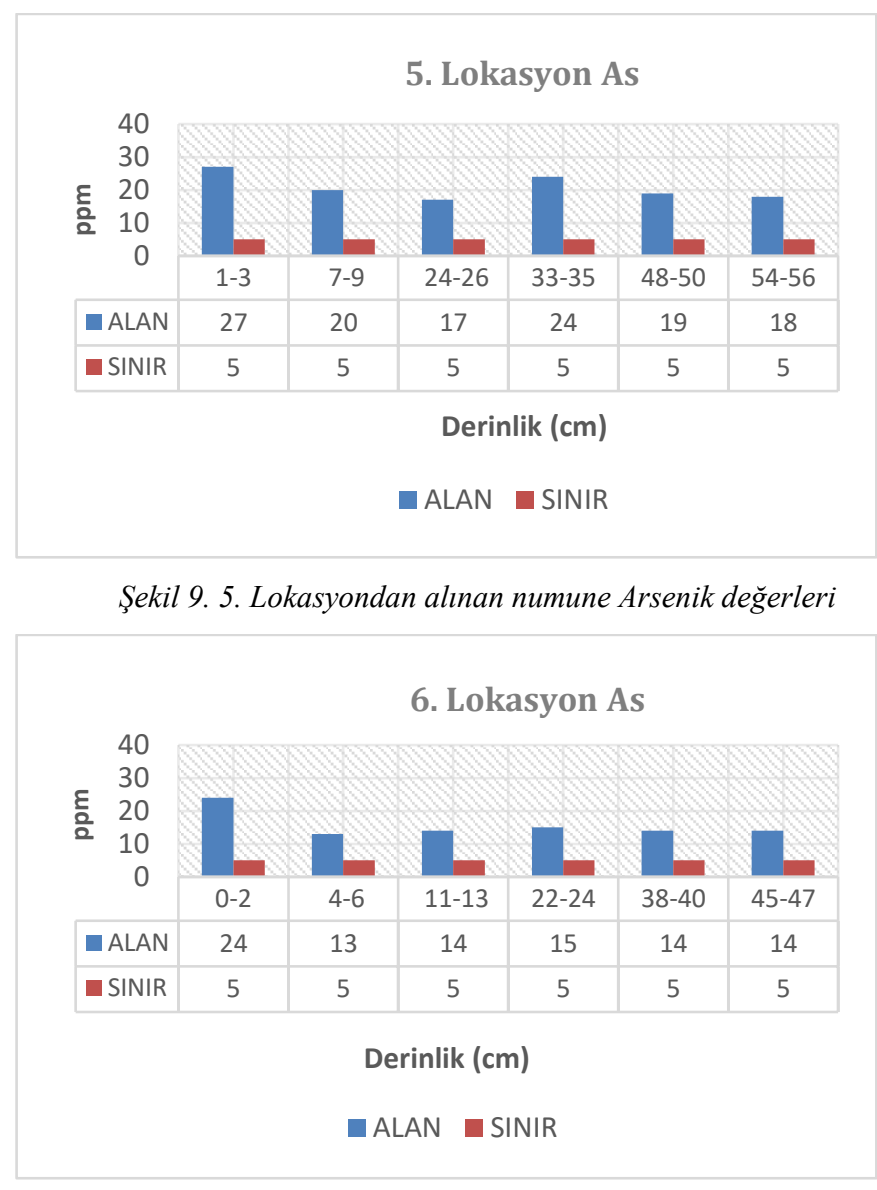

Şekil 10. 6. Lokasyondan alınan numune Arsenik değerleri 


\section{Lokasyon As}

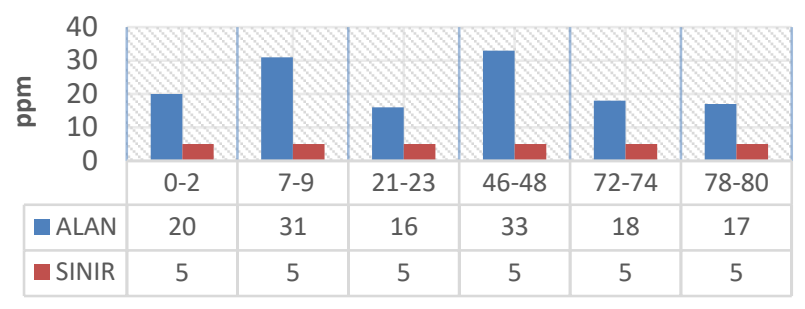

Derinlik $(\mathrm{cm})$

ALAN $\square$ SINIR

Şekil 11. 7. Lokasyondan alınan numune Arsenik değerleri

Hidrolojik döngü dikkate alınırsa kontaminantın sudaki miktarı \%1'den az olarak belirlenirken, sedimentteki oran ise \%99'un üzerindedir [15]. Bu yüzden sediment kontaminasyonun değerlendirilmesinde önemli bir indikatördür [16]. Ayrıca, değişen ortam şartları ile beraber sedimentte depolanan kontaminantlar tekrar suya karışarak, sudaki kontaminant konsantrasyonunu arttırmaktadırlar. Böylelikle sediment sudaki kirlilik için ikinci bir kaynak oluşturmaktadır. Bu sebeplerden ötürü sedimentteki metal miktarlarının analiz edilerek, insan kaynaklı yani antropojenik etkinin araştırılması ve yüksek oranda biriken metalin canlılar üzerinde gösterdiği toksik etkinin değerlendirilmesi için pek çok farklı yöntem ve sınır değerler belirlenmiştir. Ancak sediment içerisindeki ağır metal birikiminin karmaşık kimyasal içeriğinden dolayı dünya genelinde kabul edilmiş sediment kalite standartları mevcut değildir [17].

Bu çalışma kapsamında elde edilen Arsenik değerleri Tablo 2.'de sunulan skalalar ve sinır değerler ile birlikte değerlendirilmiştir. Tablo 2'de PEL, Olası etki seviyesi, TEL: Sınır etki seviyesi [18], ERM: Etki aralığ ortancası, ERL: Etki aralığı alt sınırı [19], Ref: Endüstri öncesi referans değerler [20] olarak ifade edilmektedir.

Tablo 2. Kirlilik ölçekleri ve sınır değgerler [3]

\begin{tabular}{|l|c|c|c|c|c|c|c|c|c|c|c|c|}
\hline \multicolumn{10}{|c|}{ Sınır Değerler } \\
\hline PEL & 197 & Pb & Zn & Ni & Mn & Fe & As & Cd & Cr & Al & Hg \\
\hline ERM & 390 & 110 & 270 & 50 & & & 85 & 9 & 145 & & 1.3 \\
\hline TEL & 35 & 35 & 123 & 18 & & & 5.9 & 0.6 & 37.3 & & 0.17 \\
\hline ERL & 70 & 35 & 120 & 30 & & & 33 & 5 & 80 & & 0.15 \\
\hline Ref. & 45 & 20 & 95 & 68 & 850 & 47200 & 13 & 0.3 & 90 & 80000 & 0.4 \\
\hline
\end{tabular}

Arsenik elementine ait analiz sonuçlara göre Şekil (5-11) değerlendirildiğinde, en yüksek değer $33 \mathrm{mg} / \mathrm{kg}$, olarak 4. ve 7 . lokasyonlardan alınan numuneler üzerinde görülmüştür. minumum değer ise $11 \mathrm{mg} / \mathrm{kg}$ olarak 1. Lokasyon üzerinden alınan numunede tespit edilmiştir. Tablo 2' de PEL, TEL, ERL ve Ref. sınır değerleri esas alındığında, tüm lokasyonlarda Arsenik için TEL sınır değerinin aşıldığı görülmektedir. İkinci lokasyondan alınan örselenmemiş numune üzerindeki tüm seviyelerde PEL ve Ref. sınır değerlerinin aşıldığ edilmiştir. Tüm lokasyonlardan alınan örneklerdeki Arsenic değerleri ERM sınır değerlerinin altında kaldığı görülmektedir. Herbir lokasyon için oratalama As değerleri esas alındığında, 1., 2., 3., 4., 5., 6. ve 7. Lokasyonlar için sirasıyla, $16,67 \mathrm{mg} / \mathrm{kg}$, $23,34 \mathrm{mg} / \mathrm{kg}, 21,5 \mathrm{mg} / \mathrm{kg}, 22,5 \mathrm{mg} / \mathrm{kg}, 20,84 \mathrm{mg} / \mathrm{kg}, 15,67 \mathrm{mg} / \mathrm{kg}$, ve $22,5 \mathrm{mg} / \mathrm{kg}$ olarak tespit edilmiştir. $\mathrm{Bu}$ değerler göre, 2. Lokasyonun en yüksek ortalama As değerine sahip olduğu 6. Lokasyonun ise en düşük ortalama As değerine sahip olduğu belirlenmiştir.

\section{Sonuç}

Bu çalışmada, Nevşehir H. B V. Üniversitesi NEUBAP14F4 Numaralı bilimsel araştırma projesi kapsamında 2014 yılı Haziran ayında gerçekleştirilen saha çalışmaları ile Kızılırmak Nehri üzerinde belirlenen, 7 örnekleme noktasında, Eijkelkamp Multisampler Bozulmamış Sediment Örnekleyici kullanılarak nehir tabanından bozulmamış sediment karot örnekleri alınmıştır. Alınan örneklerde seviyelere göre As (Arsenik) metal konsantrasyonları belirlenerek, sediment ortamlarının Arsenik kirliliği bakımından ön değerlendirmesi gerçekleştirilmiştir. Arsenik elementine ait analiz sonuçları değerlendirildiğinde, en yüksek değer $33 \mathrm{mg} / \mathrm{kg}$, olarak 4. ve 7. lokasyonlardan alınan numuneler üzerinde belirlenmiş, minumum değer ise $11 \mathrm{mg} / \mathrm{kg}$ olarak 1. Lokasyon üzerinden alınan numunede tespit edilmiştir. PEL, TEL, ERL ve Ref. sınır değerleri esas alındığında, tüm lokasyonlarda Arsenik için TEL sınır değerinin aşıldığ 1 görülmektedir. İkinci lokasyondan alınan örselenmemiş numune üzerindeki tüm seviyelerde PEL ve Ref. sınır değerlerinin aşıldığı tespit edilmiştir.

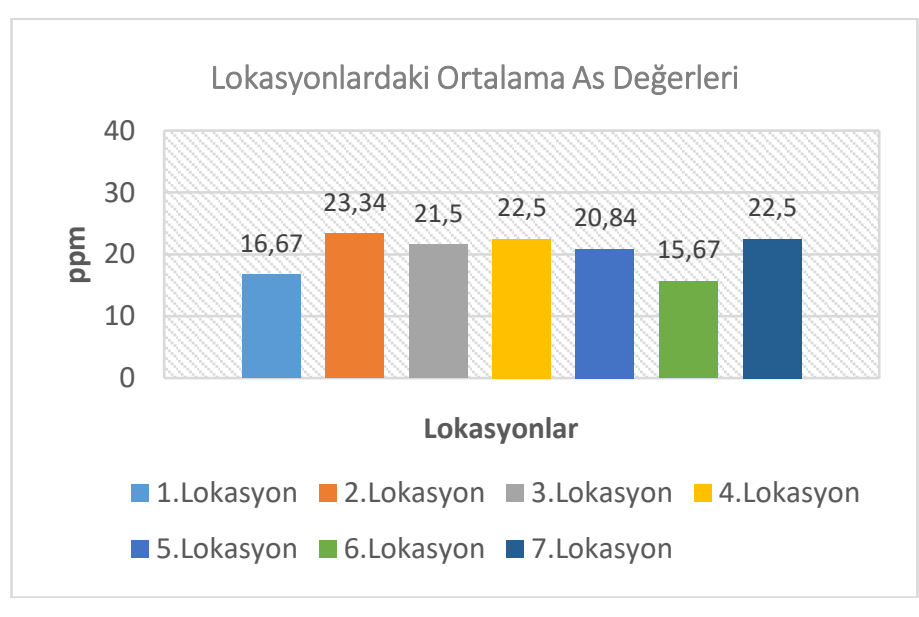

\section{Şekil 12. Saha çalı̧̧mlarında tüm loksayonlardan alınan numunelerde ortalama Arsenik değerleri}

Tüm lokasyonlardan alınan örneklerdeki Arsenik değerleri ERM sınır değerlerinin altında kaldığı görülmektedir. Şekil 12 incelendiğinde, herbir lokasyon için oratalama As değerleri, 1., 2., 
3., 4., 5., 6. ve 7. Lokasyonlar için sırasıyla, 16,67 mg/kg, 23,34 $\mathrm{mg} / \mathrm{kg}, 21,5 \mathrm{mg} / \mathrm{kg}, 22,5 \mathrm{mg} / \mathrm{kg}, 20,84 \mathrm{mg} / \mathrm{kg}, 15,67 \mathrm{mg} / \mathrm{kg}$, ve $22,5 \mathrm{mg} / \mathrm{kg}$ olarak tespit edilmiştir. Bu değerler göre, 2. Lokasyonun en yüksek ortalama As değerine sahip olduğu 6. Lokasyonun ise en düşük ortalama As değerine sahip olduğu belirlenmiştir. Ön araştırma niteliğindeki bu çalışma ile birlikte, gelecekte saha çalışmalarının gerçekleştirildiği lokasyonlardan alınan mevcut örnekler için, $\mathrm{Pb}, \mathrm{Cu}, \mathrm{Cr}, \mathrm{Ni}, \mathrm{Mn}, \mathrm{Al}, \mathrm{Fe}, \mathrm{Zn}$ ağır metallerinin detaylı analizlerinin gerçekleştirilmesi planlanmaktadir.

\section{Teşekkür}

Bu çalışma, Nevşehir Hacı Bektaş Veli Üniversitesi, BAP birimi tarafindan NEUBAP14F4 nolu projeyle desteklenmiştir.

\section{Kaynakça}

[1] Akın, M, Akın G. (2007). Suyun Önemi, Türkiye'de Su Potansiyeli, Su Havzaları Ve Su Kirliliği. Ankara Üniversitesi Dil ve Tarih-Coğrafya Fakültesi Dergisi 47, 2 (2007) 105-118.

[2] Özbolat, G, Tuli, A., (2016). Ağır Metal Toksisitesinin İnsan Sağlığına Etkileri. Arşiv Kaynak Tarama Dergisi, 25 (4) , 502521. DOI: $10.17827 /$ aktd.253562

[3] Balık, I, Tunca, E. (2015). A Review of Sediment Contamination Assessment Methods. Turkish Journal of Maritime and Marine Sciences, 1 (1) , 7-17.

[4] Idris, A.M, (2008). Combining Multivariate Analysis and Geochemical Approaches for Assessing Heavy Metal Level in Sediments from Sudanese Harbors Along The Red Sea cost, Microchemical Journal, 5.

[5] Arıman S, Bakan G. (2010). Assessment Of Heavy Metal Levels In Sediments Of The Mid-Black Sea Coast Of Turkey". 15th International Conference on Heavy Metals in the Environment; 19-23 September, pg. 472-474, Gdansk, Poland.

[6] World Health Organization. (2001). Fact Sheet No. 210. http://www.who.int/inf- fs/en/fact210.html.

[7] Çalışkan, M, Pala, A. (2009). İçme Sularında Arsenik Kirliliğii: Ülkemiz Açısından Bir Değerlendirme. Pamukkale Üniversitesi Mühendislik Bilimleri Dergisi, 15 (1), 69-79.

[8] Yazıcı, M. ve diğg. (2015). Kayseri Kenti Yer Altı Sularının Arsenik Kirliliği Açısından Değerlendirilmesi. Karaelmas Science and Engineering Journal 5(1), 16-25.

[9] Topal, M, Arslan Topal, E. (2015). Elazı̆̆ Keban Baraj Gölünde Arsenik Kirlenme Düzeyinin Belirlenmesi. Bitlis Eren Üniversitesi Fen Bilimleri Dergisi, 3 (2) , 154-161. DOI: 10.17798/beufen.62501.

[10] Üçüncü Tunca, E. (2016). Beyşehir Gölü'nde Su ve Sedimentte Ağır Metal Birikimi ve Sedimentte Antropojenik Kontaminasyon Değerlendirmesi. Ordu Üniversitesi Bilim ve Teknoloji Dergisi, 6 (2) , 205-219.

[11] Akyıldız, M, Karataş, B. (2018). Adana Şehir Merkezindeki Topraklarda Ağır Metal Kirliliğinin Araştırılması. Çukurova Üniversitesi Mühendislik-Mimarlık Fakültesi Dergisi, 33 (2), 199-214. DOI: 10.21605/cukurovaummfd.509559.

[12] Wang, J. Baskaran, M. Kumar, A. et al. (2020) Reconstruction of temporal variations of metal concentrations using radiochronology $\left({ }^{239+240} \mathrm{Pu}\right.$ and $\left.{ }^{137} \mathrm{Cs}\right)$ in sediments from Kizilirmak River, Turkey. J Paleolimnol 65, 137-149.

[13] TUBITAK (2010). Watershed protection action plan project for the Kizilirmak River Basin-final report. The Scientific and Technological Research Council of Turkey. Marmara Research Center, Kocaeli, Turkey, p 529 (in Turkish and English (some parts)).

[14] Bakan, G, Özkoç, H, Tülek, S, Cüce1t, H. (2010). Integrated Environmental Quality Assessment of the Kizılirmak River and its Coastal Environment. Turkish Journal of Fisheries and Aquatic Sciences, 10 (4) , . Retrieved from https://dergipark. org.tr/en/pub/trjfas-ayrildi/issue/13275/160380

[15] Salomons, W. \& Stigliani, W.M. (1995). Biogeodynamics of Pollutants in Soils and Sediments: Risk Assessment of Delayed and Non-Linear Responses. Heidelberg: SpringerVerlag. ISBN 3-530-58732-2.

[16] Zamani Hargalani, F., Karbassi, A., Monavari, S.M. et al. (2014). A novel pollution index based on the bioavailability of elements: a study on Anzali wetland bed sediments. Environ Monit Assess 186, 2329-2348.

[17] Yuan, Z., Taoran, S., Yan, Z., Tao, Y., (2014). Spatial distribution and risk assessment of heavy metals in sediments from a hypertrophic plateau lake Dianchi, China. Environmental Monitoring and Assessment 186: 1219-1234.

[18] Smith, S. L., Macdonald, D. D., Keenleyside, K. A., Ingersoll, C. G., Field, L. J., (1996). A preliminary evaluation of sediment quality assessment values for freshwater ecosystems. Journal of Great Lakes Research 22: 624-638.

[19] Long, E. R., Morgan, L. G. (1991). The potential for biological effects of sediment-sorbed contaminants tested in the National Status and Trends Program. NOAA Technical Memorandum NOS OMA 52. National Oceanic and Atmospheric Administration, Seattle, WA, 175 pp appendices.

[20] Turekian, K. K.,Wedepohl, K. H., (1961). Distribution of the Elements in some major units of the Earth's crust. Geological Society of America, Bulletin 72: 175-192. 